\title{
MICROPALEONTOLOGY NOTEBOOK
}

\section{A secondary stage design for the preparation of microfossils for the SEM STEPHEN TATMAN}

\author{
Micropalaeontology Research Unit, \\ Institute of Earth Studies, University of Wales, Aberystwyth, Dyfed, SY2.3 3DB.
}

The preparation of microfossil specimens for study with the scanning electron microscope involves the transfer of material from slides to stubs. Specimens must then be oriented and mounted securely. To do this accurately the slide and stub should both be viewed through a stereomicroscope. However due to differences in shape and height, both surfaces are not usually in the plane of focus at the same time. Many micropalaeontologists routinely use small boxes or sample tube lids to hold the stub and refocus before finally mounting the specimens. The risk of dropping specimens is reduced by using a single carrier, securely holding both the slide and stub. The design illustrated below (fig.1) was developed from a prototype constructed from cardboard and plastic. The metal unit can easily be made in a workshop at a very low cost or cardboard versions made in the laboratory.

The stage is based on the principle that both slide and stub should be held securely, close together and in the same plane of focus. The slide holders should be secure but not too tight otherwise the stub may be jarred as slides are changed. The number of slides which can be held on one unit may be varied. The presence of two holders has proved useful, any more could make the unit cumbersome. If the microscope to be used does not have a wide stage then it may prove more practical to have only one holder.

The stub holders allow the stub to be clamped to avoid unwanted rotation while specimens are oriented. Again the presence of two stub holders may be useful although there is an increased risk of accidentally brushing material off one while working on the other. This design is does not allow for a wide variation in the thickness of the slides. Once the microscope has been focused on the slide, the stub may be slightly raised to bring it into focus, before being secured in position using the grub screw. If a range of different slides are to be used regularly, it may be necessary to modify the design to allow for accurate adjustment of the height of the stub holders.

\section{MATERIALS AND CONSTRUCTION}

(Part numbers refer to figure $1 \mathrm{a}$. Dimensions are in $\mathrm{mm}, \mathrm{w} \times \mathrm{d} \times \mathrm{h}$ ) \#1 Base plate: (one) aluminium $80 \times 76 \times 6$

\#2 Slide supports: (two) aluminium $54 \times 21 \times 6$

\#3 Slide plate: (one) aluminium $76 \times 54 \times 6$

\#4 Slide holders: (two) standard aluminium slide bases

\#5 Stub holders: (two) aluminium $12 \mathrm{~mm}$ diameter bar $\mathrm{x} \sim 10 \mathrm{~mm}$ (see text)

\#6 Stub screws: (two) 2M bolts

\#7 Base cover: (one) self adhesive felt $80 \mathrm{~mm} \times 76 \mathrm{~mm}$

Adhesive: epoxy resin

Paint: matt black enamel

The cardboard prototype was too light and hence easily jarred. Aluminium is easily worked and is most suitable for the body of the unit. The original metal unit was constructed using recessed bolts but this is unnecessary as there is no stress on the joints. It is recommended that an epoxy resin ('Araldite' or similar) is used throughout the construction, provided surfaces to be glued are scored to provide a key. The four rectangular plates should be cut to size and then assembled. The two slide holders should then be glued into place. If the slides to be used are other than the cardboard type which are normally mounted in aluminium bases (for example plastic types) then the holders will have to be made to suit. At this stage an empty slide (of the type most often used by the user concerned) should be slid into one of the holders and the height of the slide surface from the top of the base plate determined using a micrometer (see fig. 2). The stub holders should then be machined to this dimension ' $A$ ' minus both the thickness of the stub ' $B$ ' (taking into account the mountant used e.g. double-sided tape) and the thickness of the base plate ' $\mathrm{C}$ '. A $3 \mathrm{~mm}$ diameter hole was drilled through the centre of each holder to accommodate the mounting pin of the stub. To prevent any unwanted movement of the stubs while positioning specimens a second hole was drilled $2 \mathrm{~mm}$ from the top, perpendicular to the central bore. A $2 \mathrm{M}$ thread was tapped in the second hole to take a locking screw. If it is not possible to cut such a fine thread then thin self-tapping screws may be substituted. The stub holders should then be glued in place with the locking screws facing to the side. To avoid reflected glare from the slide holders the metal version was sprayed with a matt black enamel paint ('Humbrol' or similar). When dry the self adhesive felt should be stuck to the base. This protects the stage of the microscope from scratching and allows the secondary stage to move smoothly

\section{USING THE SECONDARY STAGE}

Unlike some other mechanical aids which have been proposed for micropalaeontological work the secondary stage described in this paper does not require any changes to normal working practices. The specimens are still manipulated with a fine, wet brush while viewed through a stereo microscope. The microscope is initially focused on the specimen in the slide, which is then picked up with the brush and the secondary stage is then slid away from the user until the stub is in the field of view. The specimen may then be placed on to the stub. The stage allows the specimens to remain in the plane of focus at all times and reduces the distances that they have to be moved. This may be of particular use to those working with type material, where there is concern over the security of individual specimens.

\section{ACKNOWLEDGEMENTS}

I would like to thank lan Boomer for his constructive comments and Mike Jones for his assistance with the figures.
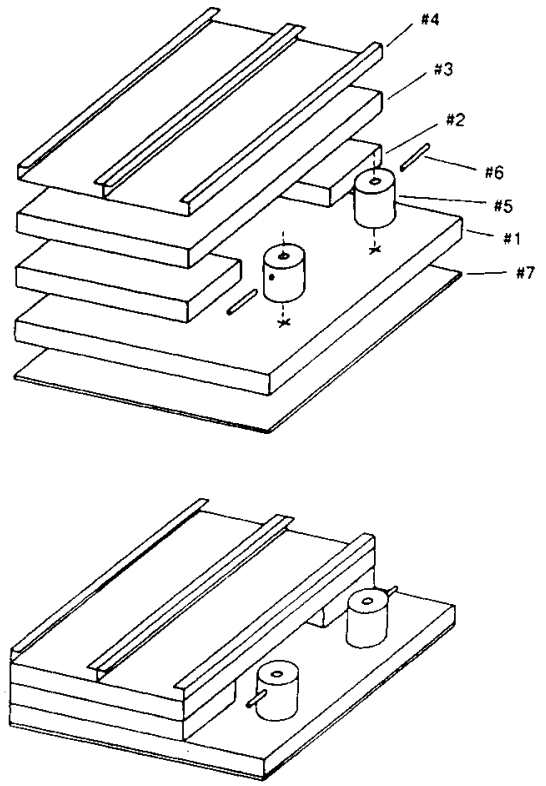

Fig.1a Exploded diagram showing components of stage. Fig.1b Completed stage slide

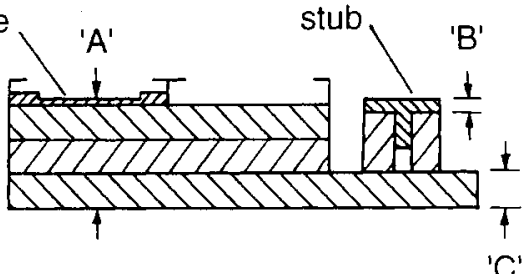

'C'

Fig.2 Section showing measurements for calculating height of stub holder 